\title{
THE ROLE OF LIMITS IN ARISTOTLE'S CONCEPT OF PLACE
}

\section{Jacqueline Mariña}

\section{Yale University}

In this paper I hope to elucidate some considerations governing Aristotle's notion of place as developed in the Physics. It is, in fact, these considerations which betray the profound nature of Aristotle's thought with respect to this issue, even though his own solution to the problem of place is itself highly inadequate.

Aristotle begins his discussion of place with the words, "For everyone supposes that things that are are somewhere, because what is not is nowhere-where, for instance, is a goatstag or a sphinx?" 1 This assertion is full of meaning, at once delimiting and channeling at the outset the direction of Aristotle's thoughts about place. A distinction is introduced in passing between that which can be thought, but which is not (such as a goat-stag or a sphinx) and that which is. That which is must be somewhere; being somewhere or having a place is thus a necessary precondition for our predicating objective (as opposed to merely ideal) reality to a thing. This condition thereby serves as a criterion through which to distinguish between objectively real and imaginary entities. This thought is not explicitly taken up again by Aristotle in his discussion of place, but it relates in important ways to the rest of the discussion; in fact, it serves as a presupposition through which Aristotle rejects both Platonic and Atomistic understandings of space.

Aristotle's assertion is reminiscent of Plato's words in the Timaeus at $52 \mathrm{~b}$, "And there is a third nature, which is space and is eternal ... which we, beholding as in a dream, say of all existence that it must of necessity be in some place and occupy a space, but that which is neither in heaven nor in earth has no existence."2 Hence, Aristotle's words are not only

Jacqueline Mariña is a graduate student at Yale University, Department of Religious Studies. At present she is completing her dissertation on Kant's ethics and philosophy of religion. She received an M. Div. from Yale Divinity School and is coauthor with Louis Dupré of "Faith in Philosophy," which appeared in Handbook of Faith (1990). 
a general remark concerning place, but at the same time serve to underline differences between his own physical realism and Plato's philosophy, which assigned a kind of reality to space itself, but denied it to the appearances in space. ${ }^{3}$

Aristotle's next consideration concerning place can also be illuminated by placing it in the context of his debate with Plato. Aristotle writes: "Of change, the most general and basic kind is change of place, which we call locomotion." For Plato, the amorphous substratum of space acquires a quasi reality precisely because space itself does not change, whereas the appearances which succeed each other in space do. Space as an unchangeable substratum must thereby be more real, for unchangeability, according to this view, is the ultimate criterion for what is real. The things in space, precisely because they succeed each other in place (that is, they "become in place and vanish out of place"5) are not apprehended by mind, but are the subject matter of true opinion; they are the changeable, and as such not absolutely real. While it is not easy to gauge what precisely Plato had in mind in staking out this position, what he meant can be illumined through one of his own metaphors. Imagine, for instance, a screen, or the wall inside the cave of Plato's Republic. Given only this limited amount of space on which shadows succeed each other, the wall itself would seem to be that which is most real, since the play of flickering images and shadows reflected upon it are in a constant state of becoming, such that it is impossible to identify an image as itself perduring through time and as the subject of change. Were this metaphor literally applicable to our apprehension of appearances, we could only have real knowledge of the substratum (i.e., the wall) on which these images appear, for only this substratum could be said to be continuously identifiable. The images themselves would be more difficult to identify continuously, since not only would they be in a constant state of becoming, but at times they would disappear completely from view, only to appear later on at another moment, but with no continuity between their disappearance and reappearance. Thus the subject of change would be the substratum on which the images appear, with the images themselves being merely accidental qualities of the substratum, i.e., that which changes of the substratum. ${ }^{6}$

It is with this Platonic perspective in mind that we must gauge the revolutionary nature of Aristotle's physical realism, and it is in this context of Aristotle's debate with Plato that we are to make sense of Aristotle's assertion that the most general and basic kind of change is change of place. In opposition to the view that space is more real than the things 
appearing in it and that it is a kind of receptacle for the ideas, we have the view that physical bodies change in respect of place. But to say that a physical body changes in respect of place, that this is the most basic sort of change, is to say something very different from Plato. For change presupposes the identity with itself of that which changes; change of place is the most basic kind of change because it preserves all the qualities of a thing (both substantial and accidental) except for location; it is the change most preserving of the identity of the thing which changes, that is, doing the least violence to the identity of the changing thing. Thus a major shift in thought has taken place; instead of asserting that space is most real because unchangeable, the things in space are thought of as real, and as identifiable despite change of place. Place thereby becomes the most accidental property that can be ascribed to a thing; in asserting the ongoing identifiability of a thing despite its change with respect to place, a whole new paradigm has been introduced. No longer is space itself that which is most substantial, so that what appears in space is accidental to it, but the things in space are themselves substantial, that is, preserving their identity despite change of place.

At 208b 1 a parallel consideration is introduced, one which, however, moves in an opposite direction, thereby revealing the dialectical nature of Aristotle's thought. Whereas in the first paragraph place is related to the most basic kind of change (locomotion), thus showing place to be the most accidental property that can be predicated of a substantial entity, the second paragraph adduces considerations in favor of the reality of place. These, however, already assume what has been established before, namely, the substantiality of physical bodies. Thus that place has some sort of reality itself independent of things in place "seems to be clear from replacement: where there is now water, the air in turn is." That is, place is itself continually identifiable despite the succession of things inhabiting it. Moreover, the continued identifiability of place apart from things in place is known precisely through replacement; were there no change of substantial entities from one place to another, we should assume place to be equivalent to matter, that is, to the material extension of things occupying space. It is only because things change place that we think of place as some sort of three-dimensional extension independent of the material extension of things in place. But this in turn means that in order to have any notion of place as something knowable independently from what occupies it, we must first possess a notion of substantial entities which change place. 
Relating this back to our previous discussion (cf. in particular Cherniss's observation quoted in note 6 of this paper), this means that Plato can have no independent notion of $\chi \omega \dot{\omega} \rho \alpha$ because it is itself constituted by particular $\tau o ́ \pi o t$, themselves defined in terms of the phenomena appearing as manifestations of space. It is, in fact, this very basic presupposition of Plato's that Aristotle argues against when he states that place can be neither the form nor the matter of a thing. ${ }^{8}$ For if we accept Plato's understanding of space, then space $(\chi \omega \dot{\omega} \rho \alpha)$ is indeed amorphous matter, while place ( of as either the matter or form of an appearance, depending on how one looks at the problem. ${ }^{9}$ Tómos can be thought of in terms of matter when one thinks of it as extension itself (once the limits defining place have been abstracted); $;^{10}$ on the other hand, place is most properly defined by these limits them. selves, even though the material substrate, i.e., extension, must be presupposed as the condition of the possibility that these limits define any thing. It is important to note that Plato does not think of place simply as local position; ${ }^{11}$ in fact, Plato's толтоs can hardly mean this at all since position presupposes some thing which is in position. For Plato, however, the то́тоs as the limit of the appearance, is precisely that which defines the appearance. Once more this underlines the substantial departure of Aristotle from Platonic thought, in particular with respect to Aristotle's physical realism, wherein substantial entities can suffer change (in particular change of place) while preserving their identity. This means that the form and matter of an entity, as intrinsic to the identity of a thing, cannot be identified with the place of a thing, for a body preserves its identity while changing place. ${ }^{12}$

Just how much Aristotle's arguments are intended as a refutation of the Platonic notion of place can be noted through an analysis of the difficult passage at $209 \mathrm{a} 7 \mathrm{ff}$.:

Again, since a body has a place and a space, it is clear that a surface does too, and the other limits, for the same argument will apply: where previously the surfaces of the water were, there will be in turn those of the air. Yet we have no distinction between a point and the place of a point; so that if not even a point's place is different [from itself] then neither will the place of any of the others be, nor will place be something other than each of these. ${ }^{13}$

This passage can be interpreted in various ways, its most obvious sense being the following. Assuming, on the Platonic model, that place is the three-dimensional configuration of an extended appearance, such that the surfaces of the appearance are not only its limits (as that which defines the appearance),

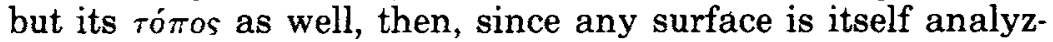
able into lines and points, there will be no distinction between 
a point and the place of a point, for all the points of the limiting surfaces are themselves constitutive of the definition of the geometric form of the appearance as well as of its place. On this view, a point (since it is constitutive of the appearance) cannot serve as an abstractable reference point through which to determine the local position of an appearance. ${ }^{14}$ Thus such a theory arrives at no scientifically useful notion of place whereby objects can be related to one another via their position relative to one another. Moreover, if we accept Aristotle's view that both a body and its surfaces must have a place (for anything that is, is in place), and if the surfaces limiting an appearance are identified with rómos, then we shall have to search for the place of a place, i.e., the place of the surfaces, geometrically conceived, delimiting a body. Another argument against the view that place can be identified with the termini of quantity (i.e., the surfaces, the lines, and the points) delimiting a thing is that since objects obviously change places, were we to accept such a definition, places would change places; this is because the surfaces of objects change place with them.

Closely related to this concept of place which Aristotle refutes is another one, equally problematic, wherein place is considered as a given magnitude, or as an interval between extremities. This view is similar to the one discussed above, with the exception that according to this understanding the interval or magnitude itself, while having the same geometrical configuration as the body that occupied it, remains behind while the body itself (as composed of both form and matter) moves along to a different place. The dependence of this view on the one formerly discussed is quite evident when one considers the difficult problem arising out of the relationship of the form of an extension with extendedness itself; while both are different concepts and can be thought to refer to different things, neither one can be thought of without the other. Limits without the extensions which they define would collapse into a single point, while pure extendedness without limits is as impossible to conceive as the infinite. Thus the notion of place as an interval is very much dependent on Aristotle's discussion of the interrelations between form and matter; matter can be defined through abstraction, for instance, "when the limit and properties of the sphere are removed, nothing is left but the matter." 15 However, as Aristotle himself notes, "it is not easy to recognize [matter and form] in separation from one another." ${ }^{16}$ By the same token, Aristotle does not have a notion of space without limits, and so when Aristotle attempts to conceive of place as something apart from the form of the object which occupied the place, he gets into 
difficulties precisely because he cannot consider place in abstraction from the limits which define it.

As Ross notes, "It is clear that the view that Aristotle is here opposing is not the view that there is one single space, distinguishable from the bodies that occupy it and move about in it." 17 In other words, insofar as his discussion of place goes, Aristotle does not consider the notion of one space from which all things in space can be abstracted. An analysis of Aristotle's rejection of a void may perhaps also include a rejection of this view, but the following may be considered reasons why Aristotle so completely overlooks this notion of space in his discussion

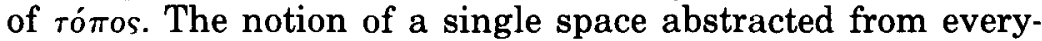
thing in it is not only difficult to conceive because no thing without limits can actually be thought, but because pure empty space has no identifiable places outside of the things which might occupy it. In order for the mind to be able to know something, this thing must be distinguished from something else; hence, delimitation, wherein at least two objects define one another, must be presupposed. Otherwise we should be as lost as on that famous night when all cows were black. However, pure empty space has no limitations, there no thing distinguishes itself from something else; there are, in effect, no things which can be apprehended, and no reference points. In other words, from a phenomenological point of view, there are no positions or places (and therefore no reference points) aside from things or already delimited extensions which can serve as reference points. Physics must thereby concern itself with a notion of place, not of space, for place is identifiable in virtue of things surrounding it and allowing it to be picked out as a particular something. This, however, means that place has limits; it has, in other words, a certain shape through which it can be identified and referred to the objects surrounding it. Thus Aristotle tells us that a thing must be equal to its place (in magnitude) and that "this kind of place is the primary place in which it is." 18 Moreover, Aristotle tells us that "it is because it surrounds that form is thought to be place, for the extremes of what surrounds and of what is surrounded are in the same [spot]. They are both limits, but not of the same thing: the form is the limit of the object, and the place of the surrounding body." 19

In the end, Aristotle's final definition of place will attempt to incorporate many of the considerations outlined above which this second view of place (i.e., place as a given magnitude) also addresses; however, Aristotle rejects this second view because of the many antinomies which it generates. It should, bowever, be noted that in accepting these considerations as valid 
for a viable conception of place, Aristotle is already committed to a view which reifies place in such a way that it is impossible to avoid an endless regress of places within places, or of places which change places. Not only this second view, but Aristotle's own definition of place is susceptible to this criticism. This is true given the following general considerations: (1) once place has been defined in terms of limits, one has, in effect, "placed" a place, for a limit is not a place (nor can it serve to constitute a place), but itself requires a place; (2) difficulties abound when these limits are in some way attached to the things inhabiting space. It is clear that although limits can be abstracted from the things of which they are limits, we should have no notion of limits apart from things which delimit one another. More importantly, however, these limits can in fact serve our purposes of allowing us to "place" objects with respect to one another only if they are attached to some real thing in the world that remains relatively fixed. The fact, however, that so many things are in motion will present real difficulties for Aristotle's conception of place.

In order to elucidate some of the thoughts outlined above, let us consider once more the view which Aristotle rejects, namely, that of place as a given magnitude separable from the object which occupies it. It is important to note that on this view the givenness of place as a magnitude depends upon the limits once defined by the surfaces of the object which occupied it. These limits cannot be abstracted from the magnitude without destroying the definition of the magnitude as this magnitude; when a magnitude is no longer defined as a particular magnitude, it is no longer a magnitude at all.

However, as Aristotle notes, were these definite magnitudes $(\delta \iota \alpha \sigma \tau \dot{\epsilon} \mu \alpha \tau \alpha)$, considered apart from the body inhabiting them, to exist, many problems would result; e.g., not only might we have concentrically overlapping places, but places might also be thought to change places. Why this is the case is explained by Aristotle at the very difficult and somewhat muddled passage at $211 \mathrm{~b} 14 \mathrm{ff}$. :

And because the thing surrounded and divided off often moves about while the surrounding thing remains (e.g., water leaves a vessel), what is in between is thought to be something, on the supposition that there is some extension over and above the body which changes position. (But that is not so: what happens is that whatever body it may chance to be, of those that change position and are such as to be in contact, comes in. If there were some extension which was what was naturally [there] and static, there would be infinitely many places in the same spot. For, when the water and air change position, all the parts will do the same thing in the whole as all the water does in the vessel, and at the same time the place will be 
moving about; so that the place will have another place and there will be many places together. ${ }^{20}$

The best way to approach Aristotle's argument is by visualizing what he is talking about. Once more it should be remembered that the $\delta\llcorner\alpha \sigma \tau \dot{\epsilon} \mu \alpha \tau \alpha$ of which he speaks are in all cases definite intervals, defined and made particular by the limits surrounding them. In the case of the $\delta\left\llcorner\alpha \sigma \tau \epsilon^{\epsilon} \mu \alpha \tau \alpha\right.$ these intervals are defined not by the form per se of the body inhabiting them, but by the surfaces of the container which are thought to be their place. Imagine, then, a bucket filled with water (diagram A). Now supposing that half the water were poured out of the vessel (diagram B) we should have two different $\delta \iota \alpha \sigma \tau \tau^{\prime} \mu \alpha \tau \alpha$ defined by the place of the water, and, in fact, since the two $\delta \iota \alpha \sigma \tau \epsilon \hat{\epsilon} \mu \alpha \tau \alpha$ overlap, we should be left with the strange situation of a place inside a place.

Interval 1 (ABCDEFGH) is defined by the containing surfaces of the bucket, and the surface of the air which forms the plane $\mathrm{ABCD}$. The same is true, respectively, of interval 2 (EFGHIJKL). However, interval 2 is different from interval 1, for according to this view, the identity of an interval is closely tied up with its form. These intervals cannot themselves define place. This is because, simply from their definition (insofar as this relates to their form), we should never know that the two intervals partly coincide; we know of this coincidence through a knowledge of place extrinsic to the definition of these intervals as "places" and as particular and identifiable intervals. Moreover, according to this view, any thing in place itself defines a new interval so that, if, for instance, the bucket of water were tipped sideways, the form of the water as defined by the surfaces of the bucket and air which surround it would create a new $\delta \iota \alpha \sigma \tau \tau^{\prime} \mu \alpha \tau \alpha$ and therefore a new place (diagram C).

In his Commentary on Aristotle's Physics, Thomas Aquinas sheds some light on this obscure passage when he writes:

But if there could be some intermediate containing space, which is other than the dimensions of the contained body, and which always remains in the same place, then this inconsistency would follow-an infinite number of places would be together. This is so because since water or air or any body or any part of a body would have proper dimensions, then every part will do the same thing in the whole as the water does in the vase. According to the position of those who believe in space, while the water as a whole is in the vase, there are other dimensions of space besides the dimensions of the water. However, every part is contained by the whole as that which is located is contained by the vase. They differ only in that the part is not divided, while that which is located is divided. Therefore if a part is actually divided, it follows that other dimensions of the whole container are there besides the dimensions of the part. ${ }^{21}$ 

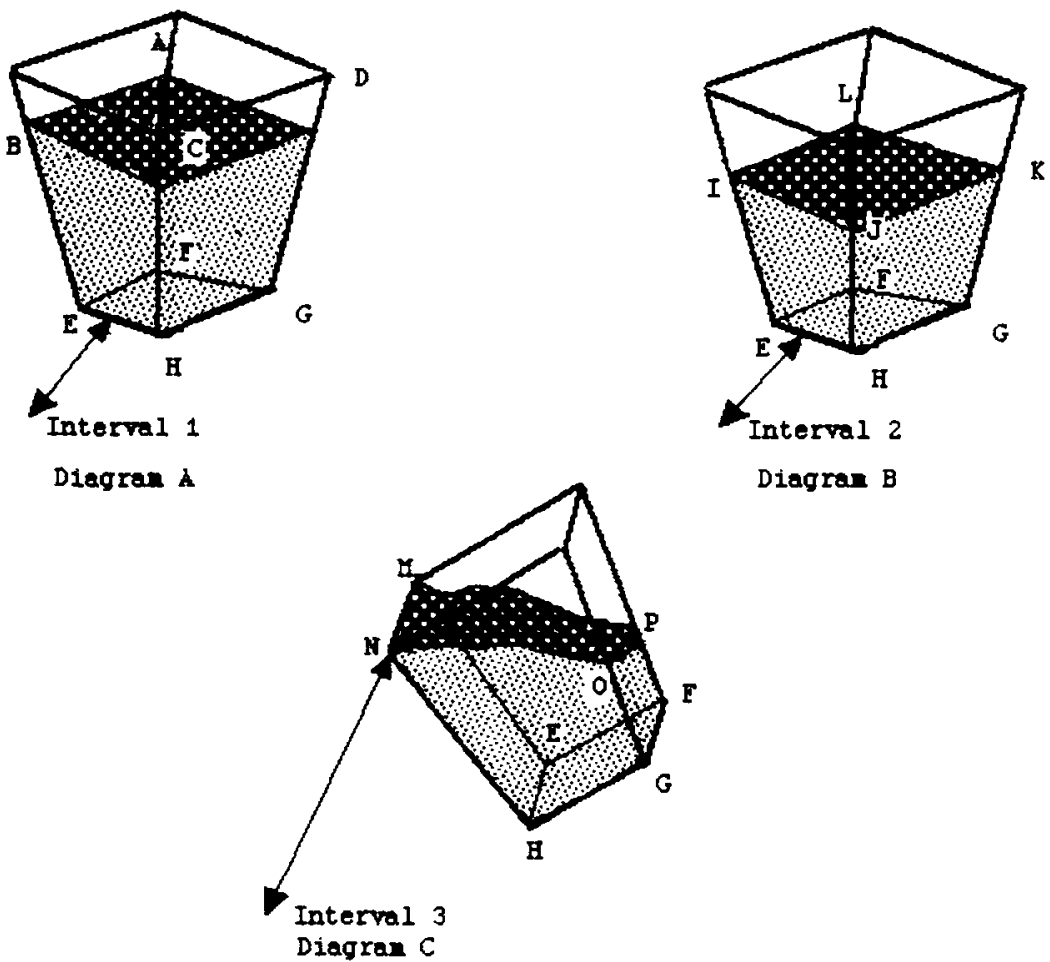

Thomas's commentary serves to elucidate yet another difficulty that arises out of the view of place as self-subsistent $\delta\llcorner\alpha \sigma \tau \hat{\varepsilon} \mu \alpha \tau \alpha$, namely, that since any part of the water which is itself divisible will constitute an interval, there will be places within places, since the interval constituted by the divisible part of the water will itself be in the container. This can be seen by referring to diagrams $A$ and $B$ above: diagram B contains a part of the water represented in diagram $A$, yet although according to this view the water in diagram $B$ can be thought of as in interval 2, this interval is itself in interval 1. Thus a series of concentric places has been generated. This is the meaning of Thomas's phrase, "then every part will do the same thing in the whole as the water itself does in the vase."

Thomas's commentary is revealing in that it shows why Aristotle wants to avoid the idea that a part continuous with that which surrounds it has a place. Aristotle writes:

So that when that which surrounds is not divided from, but continuous with, [the thing surrounded], the latter is said to be in the former not as in a 
place but as the part is in the whole; but when that which surrounds is divided from and in contact with [the thing surrounded], the latter is in the extreme of the surrounding thing first.... And if the thing surrounded is continuous it is moved not in [the surrounding thing] but with it; if it is divided, it is moved in the latter-just as much, whether or not the surrounding thing is itself moved. ${ }^{22}$

Any given part of the water would not, on Aristotle's view, have a place, for it is surrounded by matter of the same kind as itself. Only when two bodies are contiguous can the surrounded body be said to have a place, and this requirement of actual contiguity will also imply that a place is not a selfsubsistent interval, since the interval requires a surrounding body to define it. Contiguity, for Aristotle, is a special case of continuity, and not vice versa; as H. R. King notes, "the class of things continuous must not be looked upon as a species of things contiguous." ${ }^{3}$ While contiguity presupposes continuity, it adds the further requirement that two distinct entities touch at their extremes. Whereas the parts of the water are continuous with one another, they are not contiguous to each other, and cannot, therefore, be thought of as each having its own place.

The elimination of the idea that a part of a continuous body has a place partially serves to prevent the multiplication of concentric places, but this multiplication is only avoided if the notion of place as a self-subsistent interval is also jettisoned. Place therefore depends on two things, the notion of contiguity, and that which is implied by this notion, the actual physical presence of that which surrounds. Only a body which is actually surrounding and contiguous with another body can be said to constitute its place. Place thus depends on the actual situation of real bodies in contact with one another. Here we arrive at Aristotle's own first definition of place, i.e., place is the limit of the surrounding body. ${ }^{24}$ This eliminates all geometrical abstractions from actual situations in the notion of place.

Aristotle's own first definition of place is fraught with many problems which he himself recognizes, i.e., that actual surrounding bodies are often themselves in movement. At 212 a 20 he revises his definition of place: "place is the first unchangeable limit of that which surrounds." 25 This revised notion of place gives up the requirement that a place be equal in magnitude to the thing which occupies it; place is no longer a container but a fixed point. How can we make sense of Aristotle's use of the word "limit" in this context, particularly in light of the fact that an "unchangeable limit" is often quite far removed from the thing for which it is supposed to serve as a place? In the case of the boat traveling downstream, for instance, the banks of the river, as well as its bed, would serve 
the purpose of situating the boat. But are these really limits of the boat? Certainly they do not spatially define the geometrical configurations of the boat. But if this is the case, how are we to relate the banks of the river to the boat itself? What is the space through which these lines of relationship can be drawn? It is precisely at this point that Aristotle's revised notion of place breaks down.

Let me conclude with some general remarks which might get to the bottom of why Aristotle's definition of place is so unsatisfactory. I began this essay with Aristotle's contention that everything that is, is in place. Perhaps, had Aristotle thought more deeply about the ramifications of this statement, he might have arrived at a more satisfactory notion of place. For what this implies is that everything that is, being in a place, can be related to everything else that is. Such a possibility of spatial relationship among things presupposes one space through which existing things can be related. In virtue of its unitary nature, such a space could not be thought of as having limits, for to assign it limits would be, in fact, to "place" it in another, broader horizon of space. Aristotle would no doubt have serious qualms about the very possibility of thinking such a limitless space, some of which have been discussed above. Yet words such as continuity and contiguity only make sense in virtue of such a horizon of one space. Moreover, even Aristotle's notion of place as a "first unchangeable limit of that which surrounds," as far spatially removed as it can often be from that which it is supposed to place, can only have actual significance if that which is "in place" and that which is "the place of the thing" both exist in a single space; only when such a space is presupposed can lines of relationship between the two be drawn. As my analysis of the views that Aristotle refutes with such care has attempted to show, it is Aristotle's finitism which has precluded him from considering such an idea of space in place of his idea of $\tau o ́ \pi o s$.

\section{NOTES}

1 Aristotle's Physics Books III and IV, translated by Edward Hussey (Clarendon Press, Oxford: 1983), p. 20; at 208a 29-31.

2 Timaeus, translated by Benjamin Jowett, in The Collected Dialogues of Plato, edited by Edith Hamilton and Huntington Cairns (Princeton University Press, Princeton: 1961), p. 1178, at 52b.

${ }_{3}$ This is noted by Joseph Moreau in his book L'espace et le Temps selon Aristote (Editrice Antenore, Padova: 1965), p. 12.

${ }^{4}$ Hussey, op. cit., p. 20; at 208a 31-32.

5 Timaeus, op. cit., p. 1178; at 52b.

6 The same thought is expressed by Leon Robin in his book Platon:

Ce que Platon veut dire en s'exprimant ainsi, c'est justement que son 
troisèime terme n'est pas un tel contenant; il est ce dans quoi se produisent la génération et la corruption, mais en ce sense qu'il est le sujet du Devenir; dire que ceci y entre ou en sort signifie le com. mencement ou la fin d'une existence, mais en ce sense que ce sujet, qui seul est "ceci" ou "cela" indéterminément, devient tour à tour déterminément telle chose "de telle sort." (p. 231; quoted from Cherniss, noted below)

With respect to this issue Cherniss writes:

for Plato $\chi \omega \dot{\omega} \rho \alpha$ is extension and ró $\pi o s$ any dimensional section of this extension defined by the particular phenomena occuring within it orwhat is the same thing - the characterization of $\chi \omega \dot{\omega} \rho \alpha$ by various sensible qualities at a given moment produces ró $\pi 0 \iota$ which are distinguishable qualitatively relative to one another.

Harold F. Cherniss, Aristotle's Criticism of Plato and the Academy (Russell and Russell, New York: 1962), p. 114.

7 Hussey, op. cit., p. 20; at 208b $1 \mathrm{ff}$.

8 At $211 \mathrm{~b} 5$. At 209b 11-12 Aristotle explicitly says that Plato identified space and matter, and that for him place and space are the same thing. Hussey, op. cit., pp. 23, 27.

9 Concerning this issue, Moreau's commentary is illuminating:

Dans cette physique mathématique, la matière se réduit à l'étendue, ou, plus précisément, à l'extension amorphe, les corps à des configurations géométriques; dès lors, le lieu d'un corps semblera s'identifier avec sa matière. Le lieu peut être envisagé, en effet, soit comme la limite ou l'enveloppe première d'un corps, soit comme la place qu'il occupe, la portion d'étendue comprise entre ses extrémités. Dans le premier cas, il paraît s'identifier avec la forme et le contour géométrique; dans le second, supposé que le corps n'ait d'autre matière que l'étendue géométrique, le lieu ou la place s'identifiera avec la matière. (Moreau, op. cit., p. 22)

${ }^{10}$ Hussey, op. cit., p. 22; at 209b 6-11.

11 Cherniss, op. cit., pp. 115-116.

12 Hussey, op. cit., p. 23; at 209b 20-27.

${ }_{13}$ Ibid., p. 21, at 209a 7-14.

${ }^{14}$ If my interpretation is correct, then, contra Cherniss, it would seem that Aristotle understood all too well Plato's position, and that his criticisms of Plato are just. It is, however, true that the thrust of Aristotle's criticisms of Plato depend in part for their validity on the prior acceptance of Aristotle's metaphysics of substance, itself a significant departure from Plato's thought. Concerning this point Cherniss is right.

15 Hussey, op. cit., pp. 22-23; at 209b 10-11.

${ }_{16}$ Ibid., p. 23; at 209b 20-22.

17 Aristotle's Physics with Introduction and Commentary, trans. by W. D. Ross (Clarendon Press, Oxford: 1936), p. 56.

${ }^{18}$ Hussey, op. cit., p. 26; at 211a 27-29.

19 Ibid., p. 27; at 211b $10 \mathrm{ff}$.

20 Ibid., p. 27; at 211b $14 \mathrm{ff}$.

921 Thomas Aquinas, Commentary on Aristotle's Physics, trans. by Richard J. Blackwell, Richard J. Spath, and W. Edmund Thirklel (Yale University Press, New Haven: 1963), p. 209.

22 Hussey, op. cit., pp. 26-27; at 211a 29ff.

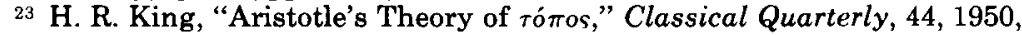
p. 82.

${ }^{24}$ Hussey, op. cit., p. 28; at 212a 5-6.

25 Ibid., p. 28; at 212 a 20. 